\title{
Adoção de Estratégias para Redução de Riscos: identificação dos determinantes da diversificação produtiva no Polo Petrolina-Juazeiro
}

\author{
Silvio Fernando Santana Oliveira Filho' ${ }^{1}$, André de Souza Melo², \\ Leonardo Ferraz Xavier ${ }^{3}$, Tiago Farias Sobel ${ }^{4}$ e Ecio de Farias Costa ${ }^{5}$
}

Resumo: O presente estudo caracteriza os produtores agrícolas do Polo PetrolinaJuazeiro segundo a adoção de estratégias de diversificação produtiva para mitigar diversos tipos de riscos. Para tanto, foram coletadas 173 observações e um modelo econométrico de logit ordenado foi aplicado para identificar os fatores que influenciam a probabilidade de o produtor diversificar sua produção. A estimação do modelo econométrico sugere que os principais fatores de influência da diversificação produtiva no polo são: porte do produtor (colono), experiência, participação da receita advinda de contratos, participação da receita advinda de atravessadores, culturas específicas (banana, coco, goiaba, manga e uva), participação em associação, acesso à assistência técnica, certificação, adoção de procedimentos pós-colheita e acesso à internet. A investigação acerca de referidas relações torna-se relevante para a formulação de políticas de incentivo à adoção de estratégias gerenciais de redução de riscos na região, atualmente preocupada com questões associadas à especialização das atividades e à vulnerabilidade dos produtores frente a choques de demanda.

Palavras-chaves: Diversificação produtiva, fruticultura, Petrolina-Juazeiro, logit ordenado.

Abstract: This paper characterizes the farmers of Petrolina-Juazeiro Polo depending on the adoption of strategies of product diversification to mitigate a variety of risks. To that end, were collected 173 observations and an econometric model, ordered logit, was applied to identify factors that influence the probability of the producer to diversify their production.

1. Mestre em Economia - Universidade Federal de Pernambuco (Pimes/UFPE). E-mail: silvioofilho@gmail.com

2. Professor de Economia da Universidade Federal Rural de Pernambuco (PADR/UFRPE). E-mail: andredesouzam@gmail.com

3. Doutor em Economia - Universidade Federal de Pernambuco (PIMES/UFPE). E-mail: leonardoferraz@gmail.com

4. Professor de Economia da Universidade Federal da Paraíba (UFPB). E-mail: tiagosobel@yahoo.com.br

5. Professor de Economia da Universidade Federal de Pernambuco (Pimes/UFPE). E-mail: ecio@yahoo.com 
The estimation of the econometric model suggests that the main factors influencing diversification of production at the pole are: size (small farmer), experience, contracts, sales to middlemen, cultivation of main crops (banana, coconut, guava, mango and grape), association, technical assistance, certification, post-harvest care and internet access procedures. The investigation of these relations becomes relevant to the formulation of policies to encourage the adoption of management strategies to reduce risks in the region, currently concerned with the specialization of activities and the vulnerability of producers face to demand shocks.

Key-words: Productive diversification, fruit, Petrolina-Juazeiro, Ordered Logit.

Classificação JEL: C25, Q14, G32.

\section{Introdução}

O Polo Petrolina-Juazeiro está na região do Submédio São Francisco e tem como foco dinâmico de sua economia a produção irrigada de frutas. A região possui as condições naturais necessárias ao desenvolvimento dessa atividade, combinando índices de insolação e calor, aliado ao clima seco do semiárido e um solo favorável à irrigação. Esses fatores permitem várias safras anuais e maior qualidade de seus produtos, tornando o polo competitivo no mercado mundial de frutas.

Nas últimas décadas, os altos volumes de investimentos públicos e privados, sobretudo em canais e sistemas de irrigação, modificaram por completo a estrutura da economia da região, formada pelos municípios de Petrolina, Santa Maria de Boa Vista, Lagoa Grande e Orocó, em Pernambuco, além de Juazeiro, Curaçá, Casa Nova e Sobradinho, na Bahia. O polo tornou-se uma ilha de desenvolvimento em meio ao semiárido nordestino. $\mathrm{O}$ desenvolvimento do setor agrícola provocou o aparecimento de indústrias tanto a montante, com a instalação de empresas fornecedoras de insumos e equipamentos; como a jusante, com a indústria de processamento e distribuição dos produtos. O setor urbano enfrentou uma transformação radical, melhorando aspectos como meios de comunicação, transporte, ele- trificação, rede de comercialização e creditícia, instalação de Distritos Industriais etc. (LIMA e MIRANDA, 2001).

Contudo, tem sido bastante frequente a discussão sobre a concentração da produção do polo em poucas culturas, seja no meio acadêmico, nas organizações de produtores ou na esfera da política agrária governamental. De acordo com o IBGE (Instituto Brasileiro de Geografia e Estatística), através da PAM (Produção Agrícola Municipal), as culturas de uva e manga correspondem, juntas, a quase $65 \%$ do valor da produção anual da região (BRASIL, 2010a). Tal concentração significa maior vulnerabilidade dos produtores frente a choques de demanda. Tratando-se de atividades agrícolas interessadas em mercados externos, essa vulnerabilidade mostra-se ainda mais preocupante, o que de fato observou-se durante a crise econômica mundial deflagrada em meados de 2008, com impactos negativos sobre a economia local. Ademais, a dificuldade de substituir a matriz produtiva com rapidez, tendo em vista os elevados investimentos com a implantação dessas culturas, termina por inibir reações a crises exógenas. Dessa maneira, é perceptível que a estratégia de diversificação produtiva na região é benéfica como ferramenta de gerenciamento de riscos e manutenção sustentável do desenvolvimento do polo.

Culas e Mahendrarajah (2005) afirmam que os fatores de risco variam de diversas formas na 
atividade agrícola, sendo este o principal problema relacionado a tal exploração. Tipicamente, as diferentes formas de risco estão associadas a fatores climáticos, pestes, doenças, incerteza de preço, mercado e comércio. Segundo os autores, a estratégia de diversificação no setor agrícola é considerada uma resposta espontânea para mitigar algumas dessas incertezas. Nesse sentido, a diversificação dos cultivos é recomendada para melhorar o gerenciamento do risco na unidade produtiva, trazer benefícios ecológicos, controlar pragas e doenças, bem como reduzir a dependência do negócio sobre uma única cultura. Como apontam Delgado e Siamwalla (1997), diversificar a produção é uma estratégia de gerenciamento para mitigar riscos de preço, bem como riscos de produção.

Segundo Bravo-Ureta et al. (2006), a racionalidade para a estratégia de diversificação é baseada nos seguintes aspectos: i) redução de risco do negócio, restringindo a flutuação de preços; ii) estabilização na produção, mitigando o potencial de ocorrência de pragas e doenças; iii) segurança alimentar, oferecendo aos produtores e à sociedade acesso a alimentos suficientes, nutritivos e seguros e iv) proteção ambiental, reduzindo o desgaste do solo. Ademais, como definem Ravisankar et al. (2005), a diversificação é um portfólio de renda de atividades com diferentes graus de risco, retornos, liquidez e sazonalidade, no qual o produtor ajusta um mix de produção de acordo com determinado ambiente. Assim, referida estratégia pode ser demarcada como uma alocação de ativos produtivos entre diferentes explorações geradoras de renda.

Dada a importância associada ao referido tema, o objetivo deste trabalho é analisar o comportamento (probabilidade) dos produtores agrícolas do Polo Petrolina-Juazeiro quanto ao gerenciamento de riscos em suas unidades produtivas, particularmente ao que diz respeito à adoção de estratégias de diversificação dos cultivos explorados na propriedade. Na dimensão deste estudo, busca-se efetuar relações entre a opção do produtor em adotar a estratégia de diversificação e variáveis socioeconômicas associadas ao mesmo, bem como características da propriedade, dentre elas tamanho e tecnologia empregada. Destarte, pretende-se identificar os determinantes da diversificação na produção agrícola do Polo Petrolina-Juazeiro, investigação relevante para a formulação de políticas de incentivo à adoção de estratégias gerenciais de redução de riscos na região, uma vez que, dispondo de tais informações, será possível identificar sob quais dos aspectos citados, próprios do produtor - tais como nível educacional, meios de comercialização, adoção de tecnologias etc. -, os formuladores de políticas locais devem focar suas atenções visando fazer com que ele se torne mais propenso à diversificação. Adicionalmente, em se tratando de um estudo de caso para uma microrregião com as características do polo, essa importância aumenta pelo elevado índice de pobreza local, contudo, com um elevado nível de competitividade da atividade frutícola, podendo esta, assim, ser vista potencialmente como um setor-chave para alavancar os indicadores sociais da região.

Dado esse contexto, para se alcançarem os objetivos pretendidos, este trabalho encontra-se organizado em quatro seções, além desta introdução: i) revisão de estudos acerca de estratégias de diversificação; ii) descrição da metodologia de pesquisa; iii) apresentação dos resultados e iv) considerações finais do estudo.

\section{Revisão teórica}

A literatura sobre diversificação é estudada desde os anos 1950. Trabalhos de Heady (1952) e Markovitz (1959) são considerados pioneiros sobre o tema ao lançarem a abordagem de média variância do portfólio. Segundo Culas e Mahendrarajah (2005), o principal propósito da diversificação na agricultura é reduzir o risco do retorno total esperado selecionando uma gama de atividades que tem retornos de correlação baixa ou negativa. Os autores afirmam, nesse sentido, que modelos de risco quadrático possuem a melhor maneira para selecionar o portfólio de culturas. 
120 - Adoção de Estratégias para Redução de Riscos: identificação dos determinantes da diversificação produtiva no Polo PetrolinaJuazeiro

Segundo McNamara e Weiss (2005), teoricamente, um produtor irá diversificar sua cultura de acordo com dois argumentos: ganhos de eficiência e redução de risco. As ferramentas utilizadas para modelar a eficiência relacionada com a decisão de diversificar a cultura são a economia de escala e de escopo do mix de culturas. Para os autores, se for menos oneroso, para um produtor, produzir bens juntamente em vez de separadamente, a função custo desse produtor exibe economias de escopo. Esse conceito é aceito por vários autores, porém, fontes de economias de escopo não são simples de se identificar. Com relação ao risco de renda, os produtores irão se beneficiar com a renda corrente mais estável. $\mathrm{O}$ trabalho de McNamara e Weiss (2005) analisa a diversificação como uma estratégia de estabilização da renda agrícola no estado de Upper (Áustria). Os resultados sugerem que a diversificação agrícola é relacionada com diversas características da propriedade: maiores propriedades tendem a ser mais diversificadas, enquanto produtores mais jovens possuem chances menores de diversificarem.

Culas e Mahendrarajah (2005) afirmam que existem várias razões que podem explicar a diversificação como opção para gerenciar incertezas. Primeiro, o relacionamento entre diversificação e tamanho da propriedade é uma indicação do trade-off entre redução de risco e retorno em uma atividade. Um produtor pode deixar um grande retorno esperado pela especialização para reduzir o risco através da diversificação. Segundo, há um grande número de variáveis de nível microeconômico que podem afetar a diversificação em um comportamento risco-preferência. Essas variáveis podem incluir formas de organização do produtor, mudanças tecnológicas e políticas, localização geográfica, emprego em outras atividades, experiência dos produtores, riqueza dos mesmos, seguro agrícola etc. Terceiro, existem instrumentos de políticas desenhados para aumentar a segurança alimentar e gerenciar o ambiente e outras fontes de maneira sustentável mais do que maximizar lucros em curto prazo. Nesse sentido, Culas e Mahendrarajah (2005) investigaram as causas da diversificação agrícola na Noruega, incorporando quatro índices de diversificação para captar o risco e as incertezas em relação à produção e à renda. Como resultado do modelo, que utilizou técnicas de dados em painel, verificou-se que grandes produtores são mais diversificados, e quando há alocação produtiva e acesso ao emprego, produtores têm um incentivo maior para propagar o risco. Esses resultados sugerem que a diversificação e tamanho da propriedade são positivamente relacionados e que não há economia de escala suficiente para garantir especialização.

Wu e Prato (2006) abordaram a diversificação como forma de eficiência econômica. Assim, os autores investigaram a eficiência produtiva para uma amostra de propriedades de uma única cultura (especializada) e propriedades diversificadas entre produção de culturas e pecuária no estado de Missouri (USA), utilizando a abordagem de fronteira de custo. Através da estimação de uma fronteira de produção não paramétrica, os autores concluíram que, na média, tanto as propriedades diversificadas quanto as especializadas se mostraram eficientes. Seguindo essa mesma abordagem, Rahman (2008a), examinou o mérito da diversificação de culturas como uma estratégia para o crescimento agrícola em Bangladesh, com resultados que revelam fortes evidências de diversificação entre a maioria das firmas e ganhos significativos de eficiência auferidos. A conclusão deste trabalho é que a diversificação é uma estratégia desejável para o crescimento da agricultura no país, sendo o desenvolvimento da infraestrutura uma política essencial para melhorar a eficiência e promover a diversificação das firmas.

Por sua vez, Coelli e Fleming (2004) estudaram as pequenas unidades produtivas de Papua Nova Guiné, onde o café é a principal commodity comercializada. Os autores ressaltam que o papel da diversificação é crucial na agricultura, o que pode influenciar a produtividade dos fatores e a eficiência na produção. Devido a uma grande quantidade de pequenos produtores que praticam agricultura de subsistência, os resultados empíricos apresentaram uma fraca economia de 
escopo gerada com a diversificação, o que refuta a ideia de que pequenos produtores praticam diversificação para ganhos de eficiência. Contudo, os autores concluíram que a estratégia de diversificação das culturas melhora significativamente a eficiência técnica nas firmas do país. Em estudos semelhantes, Llewelyn e Williams (1996) e Haji (2007) também verificaram tal relação para os casos da Indonésia e da Etiópia, respectivamente.

Rahman (2008b), sobre a economia de Bangladesh, analisou os fatores que afetam a probabilidade de os produtores desse país de adotarem sistemas diversificados de produção ou especializar-se no cultivo do arroz com tecnologia moderna. Os resultados, encontrados a partir da aplicação de um modelo probit bivariado, revelaram que a disponibilidade de irrigação é o fator mais importante para que o produtor decida pela produção especializada de arroz. A probabilidade de se adotar um sistema de cultivo diversificado, por sua vez, é significativamente maior em áreas com nenhuma infraestrutura de irrigação. Além disso, educação do produtor, experiência e renda não agrícola influenciam positivamente a opção pela diversificação. Pequenos produtores, no caso em estudo, também seriam mais propensos à adoção de sistemas diversificados.

Em estudo sobre produtores indianos, Singh et al. (2006) analisaram os determinantes da diversificação agrícola no país. Segundo os autores, esta seria influenciada por fatores tecnológicos e de infraestrutura. Dentre alguns fatores, destacam-se: quantidade de estradas por unidade de área, número de mercados regulados, número de vilas eletrificadas, área com altas variedades de colheita, percentual de área irrigada e consumo de fertilizante por hectare. Com objetivos semelhantes, Bravo-Ureta et al. (2006) estudaram produtores de El Salvador e concluíram que a diversificação agrícola é positivamente associada com o tamanho da propriedade, escolaridade, participação em associações e frequência de visitas de extensão.

Fraser (2006), por sua vez, aponta que alguns modelos têm diagnosticado que a liberalização do comércio tende a promover o processo de diversificação agrícola, enquanto outros modelos afirmam o contrário. O autor explorou essas indicações e estudou produtores da cidade de British Columbia (Canadá), onde, entre 1992 e 1998, subsídios governamentais e outras medidas foram implementadas no sentido de proteger produtores de hortifruti frente à competição externa. Os resultados indicaram que as estratégias de diversificação foram observadas com maior intensidade sobre culturas destinadas ao processamento, mas não para o mercado final. Segundo o autor, os produtores foram forçados a diversificarem suas atividades para lidar com o declínio da indústria de processamento.

Chaplin (2000) identificou uma gama mais extensa de razões que podem explicar a variação de graus de especialização e diversificação. Primeiro, os recursos disponíveis (tipo de solo, clima local, disponibilidade de água etc.) afetam as oportunidades de produção. Segundo, a medida de diversificação em mercados domésticos e mundiais influenciaria no mix de produção e, além disso, intervenções e incentivos do governo seriam determinantes. Também, produtores variam em níveis de conhecimento e perícia sobre uma atividade de produção específica. Dessa forma, um plano de cultivo além da base de conhecimento do produtor seria mais arriscado, o que implica que áreas com um histórico de monocultura tenderiam a ser mais especializadas. Terceiro, a restrição de acesso a mercados reduz o número de commodities produzidas, aumentando a propensão à monocultura. Quarto, a infraestrutura prevalecente em áreas rurais afetaria a disponibilidade de insumos e acesso ao mercado. Assim, uma infraestrutura pobre pode limitar o mix de produção e aumentar a tendência em direção à monocultura. Por fim, fatores históricos, como colonização, a qual deixava uma infraestrutura e recursos viesados para a monocultura, aumentariam a propensão à especialização.

Alguns autores também efetuaram investigações empíricas sobre a diversificação utilizando dados cross-section, como White e Irwin (1972) e Pope e Presscott (1980). De acordo com 
122 - Adoção de Estratégias para Redução de Riscos: identificação dos determinantes da diversificação produtiva no Polo PetrolinaJuazeiro

esses autores, ambiguidades existem sobre a relação entre algumas características do produtor e a diversificação de culturas. Em particular, o estudo de Pope e Prescott (1980), que utilizou medidas de diversificação sobre produtores da Califórnia (USA), revelou evidências que grandes produtores são mais diversificados, bem como produtores mais ricos, cooperados e com menos experiência tendem a ser mais especializados.

Smith et al. (2006) também estudaram os determinantes da diversificação agrícola, especificamente para a região das pradarias canadenses. Como resultados, o principal fator determinante da diversificação diz respeito ao preço relativo das culturas. Dentre outros fatores, também devem influenciar positivamente o acesso à tecnologia de produção e, negativamente, a disponibilidade de seguros e a renda bruta da propriedade. Em outro estudo, Smith e Young (2003) analisam a diversificação de culturas nos Estados Unidos e Canadá, encontrando resultados semelhantes ao trabalho de Smith et al. (2006). Por sua vez, Beninai et al. (2004) investigaram os determinantes da diversificação na Etiópia, verificando que características físicas da propriedade e perfil das famílias, tais como riqueza, educação e emprego não agrícola, possuem efeitos sobre a diversificação.

No Brasil, ainda que o agronegócio tenha importante papel sobre sua economia, não são encontrados estudos de identificação dos determinantes da diversificação agrícola. A literatura nacional relacionada à estratégia de diversificação para redução de riscos tem se restringido basicamente ao campo da Economia das Finanças, principalmente sobre a diversificação de ativos financeiros. Contudo, como pode ser apontado nos trabalhos internacionais aqui citados, a diversificação agrícola tem como principais determinantes o nível de conhecimento do produtor (educação formal e acesso a informações relacionadas à produção agrícola), o tamanho da propriedade (área e renda), a organização social (cooperativismo), bem como a infraestrutura e a tecnologia disponíveis para a produção.

\section{Metodologia}

Na presente seção, é apresentada a metodologia aplicada na pesquisa. Para tanto, serão destacados aspectos relacionados à mensuração da diversificação agrícola, ao modelo econométrico estimado e aos dados utilizados no estudo.

\subsection{Mensuração da diversificação agrícola}

Para calcular o grau de diversificação característico de cada unidade produtiva, utilizou-se o Índice de Diversificação de Simpson (SID), como proposto no estudo de Singh et al. (2006). O referido índice pode ser expresso como:

$$
S I D=1-\sum_{i=1}^{N} W_{i}^{2}
$$

Em que:

$$
W_{i}=\frac{X_{i}}{\sum_{i=1}^{N} X_{i}}
$$

$X_{i}$ representa a renda adquirida pelo produtor com a $i$-ésima cultura, enquanto $W_{i}$ é a renda proporcional auferida com a $i$-ésima cultura na renda total do produtor. Assim, quanto maior a participação das receitas com a i-ésima cultura sobre o total de renda da propriedade, mais próximo da unidade será o valor de $W_{i}$. Caso o produtor explore apenas uma cultura, o valor de $W_{i}$ será equivalente a um, enquanto o índice SID será equivalente a zero. Assim, se o SID calculado para dada firma toma o valor zero, significa dizer que a mesma caracteriza-se por total especialização em uma única cultura. Do contrário, caso o índice seja igual a um, o produtor diversifica plenamente as culturas possíveis.

Singh et al. (2006) utilizaram o Índice de Simpson tratando $X_{i}$ como a área cultivada pelo produtor com a $i$-ésima cultura. Assim, esses autores avaliaram a estratégia de diversificação através da alocação de culturas na área total da propriedade. Contudo, no presente estudo, pre- 
feriu-se calcular a diversificação levando-se em conta a renda auferida pelo produtor com cada cultura, visto que, na ótica da firma, a importância de certa cultura será dada pela renda que a mesma produz. Além disso, a diversificação é uma estratégia de redução do risco de perda de renda com a especialização. De forma pragmática, um produtor que possui $90 \%$ de sua renda total advinda de uma única cultura, caracteriza-se por forte especialização, estando intensamente sujeito aos riscos associados a esta exploração. Neste exemplo em específico, pouco importaria se essa atividade que contribui com $90 \%$ da renda total do negócio ocupasse apenas $10 \%$ da área total da propriedade, pois qualquer fator negativo que recaísse sobre essa exploração viria a comprometer uma elevada parcela das receitas da firma.

Nesse sentido, a utilização do índice descrito anteriormente tem o objetivo de mensurar a diversificação produtiva em termos de obtenção de renda com cada cultura. Assim, vale salientar que não foram estipulados valores referentes a cultivos de subsistência, bem como foram desconsideradas as áreas destinadas a plantios de teste e/ou em fase de maturação, áreas abandonadas e extensões que não tenham, por qualquer razão, aproveitamento econômico.

\subsection{Modelo logit ordenado}

Para desenvolver a análise dos determinantes da diversificação agrícola no Polo PetrolinaJuazeiro, utilizou-se, neste estudo, o modelo de regressão logística ordinal ou, simplesmente, logit ordenado. Esse modelo utiliza máxima verossimilhança ${ }^{6}$ para fornecer estimativas sobre quais fatores influenciam, no caso deste trabalho, a decisão dos produtores em diversificar sua matriz produtiva. Ao ser estimado, o modelo é capaz de fornecer os determinantes da probabilidade de a firma ser caracterizada por maiores ou menores graus de diversificação. O intuito, portanto, é

6. Os estimadores são obtidos por meio da otimização numérica de Newton-Raphson. Para mais detalhes, ver Gould et al. (2010). identificar as variáveis que elevam ou reduzem a probabilidade de um produtor diversificar sua atividade. Nesse sentido, os produtores da amostra foram estratificados segundo graus de diversificação e a variável dependente passaria a ser discreta e qualitativa, com categorias de correspondência ao Índice de Simpson descrito na subseção anterior.

Vale destacar que modelos de regressão estimados por mínimos quadrados devem ser inadequados para este tipo de análise, visto que a variável dependente (Índice de Simpson) é truncada entre zero e um. Uma alternativa seria o uso de estimação beta, mas a frequência de observações da variável dependente na cauda inferior impediria este recurso, bem como poderia justificar o uso de modelos logit em favor de probit. Como esclarecimento complementar, optou-se pelo uso de logit ordenado em vez de multinomial, tendo em vista a clara definição de estratos ordinais relacionados à variável dependente. Vale ainda destacar que não foram testados modelos tobit, tendo em vista o objetivo especial em investigar as probabilidades de utilização de estratégias de diversificação sobre as firmas do Polo Petrolina-Juazeiro.

Quanto à técnica de estimativa do modelo logit ordenado, desenvolvida inicialmente por McKelvey e Zavoina (1975), é baseada em um modelo de probabilidade linear construído em torno de uma regressão latente, em que:

$$
y^{*}=x^{\prime} \cdot \beta+\varepsilon
$$

Nessa regressão, $y^{*}$ trata-se de uma variável não observada, $x$ é o vetor de informações explanatórias, $\beta$, o vetor de parâmetros e $\varepsilon$, o resíduo.

Assim, y (com $J$ categorias) é gerada da seguinte maneira:

$$
\begin{aligned}
& y=0, \text { se } y^{*} \leq \mu_{1}, \\
& y=1, \text { se } \mu_{1}<y^{*} \leq \mu_{2}, \\
& y=2, \text { se } \mu_{2}<y^{*} \leq \mu_{3,} \\
& \cdots \\
& y=J, \text { se } \mu_{J} \leq y^{*}
\end{aligned}
$$


124 - Adoção de Estratégias para Redução de Riscos: identificação dos determinantes da diversificação produtiva no Polo PetrolinaJuazeiro

Os parâmetros $\mu$ são chamados pontos de corte das categorias, sendo desconhecidos e estimados em conjunto ao vetor $\beta$.

Assumindo que $\varepsilon$ seja normalmente distribuído entre as observações ${ }^{7}$, normaliza-se a média e a variância do resíduo para zero e um. Assim, têm-se as seguintes probabilidades:

$$
\begin{aligned}
& P(y=0 \mid x)=F\left(\mu_{1}-x^{\prime} \cdot \beta\right), \\
& P(y=1 \mid x)=F\left(\mu_{2}-x^{\prime} \cdot \beta\right)-F\left(\mu_{1}-x^{\prime} \cdot \beta\right), \\
& P(y=2 \mid x)=F\left(\mu_{3}-x^{\prime} \cdot \beta\right)-F\left(\mu_{2}-x^{\prime} \cdot \beta\right), \\
& \cdots \\
& P(y=J \mid x)=1-F\left(\mu_{1}-x^{\prime} \cdot \beta\right) .
\end{aligned}
$$

Para todas as probabilidades, deve-se ter $\mu_{1}<$ $\mu_{2}<\ldots<\mu_{\text {J }}$.

Tomando $F(\cdot)$ como uma função de distribuição cumulativa (com distribuição logística), para qualquer valor de $Z$, a função é dada por:

$$
F(Z)=\frac{\exp (Z)}{1+\exp (Z)}
$$

A regressão pode ser realizada através de diferentes técnicas, como a versão de chances proporcionais e a versão estereótipo (STATA, 2010). No caso do presente estudo, é utilizado o modelo de chances proporcionais ou proportional odds model, que inclui uma suposição de que os coeficientes de inclinação são iguais em todas as categorias. Nesse sentido, o modelo de chances proporcionais é um conjunto de equações para as probabilidades de distribuição acumulada e estima a probabilidade de ocorrência em certa categoria, dado um conjunto de características:

$$
\begin{aligned}
& \frac{P(y \leq i \mid x)}{P(y>i \mid x)}=\exp \left(\mu_{i}-x^{\prime} \cdot \beta\right) \\
& \log \left(\frac{P(y \leq i \mid x)}{P(y>i \mid x)}\right)=\mu_{i}-x^{\prime} \cdot \beta
\end{aligned}
$$

7. Greene (2003) chama atenção que outras distribuições, como a logística, podem ser utilizadas. Assume-se normalidade puramente por conveniência. Na prática, as distribuições logística e normal geralmente apresentam resultados similares.
Para ajuste do modelo, Stata (2010) sugere o teste razão de verossimilhança (teste $L R$ ) que verifica que pelo menos um dos coeficientes da regressão não é igual a zero no modelo. $\mathrm{O}$ teste pode ser calculado como a seguir:

$$
-2(l(\bmod 1)-l(\bmod 2))
$$

Em que $l(\bmod 1)$ é a função verossimilhança do modelo sem parâmetros e $l(\bmod 2)$ é o logaritmo da probabilidade do modelo com todos os parâmetros. O teste tem a distribuição $\chi^{2}$, cujos graus de liberdade são definidos pelo número de regressores no modelo. A hipótese nula do modelo é que não existem regressores.

Outro tipo de teste de ajuste de modelo é o que analisa a presença de proporcionalidade entre os pontos de corte, ou seja, o teste da razão aproximada da verossimilhança (likelihood ratio test) proposto por Wolfe e Gould (1998). A hipótese nula é que não existe diferença nos coeficientes entre os modelos. O teste é semelhante ao teste $L R$, mas difere no número de graus de liberdade, que é igual a $p(K-2)$, em que $p$ é o número de regressores e $K$ o número de categorias. A distribuição utilizada também é $\chi^{2}$. Esse teste também é sugerido para identificar a presença de heteroscedasticidade, como apontam Wang e Kockelman (2005).

\subsection{Modelo empírico e dados}

Sobre a variável dependente utilizada no modelo logit ordenado, atribuiu-se a construção de quatro categorias para definir diferentes graus de diversificação produtiva. $\mathrm{O}$ primeiro estrato refere-se a produtores com maior grau de especialização, caracterizados pelo valor calculado do Índice de Simpson (SID) correspondente ao intervalo $[0,0 ; 0,2)$. O segundo estrato, referente a uma especialização moderada, com SID no intervalo $[0,2 ; 0,4)$. A terceira classe, de produtores com SID no intervalo $[0,4 ; 0,6)$, corresponde a um grau moderado de diversificação. Por fim, o quarto segmento diz respeito a produtores diver- 
sificados, com Índice de Simpson correspondente ao intervalo $[0,6 ; 0,8]^{8}$.

Nesse sentido, a variável explicativa y é definida da seguinte forma:

$y=0$ (especialização forte), se $y^{*} \leq \mu_{1}$,

$y=1$ (especialização moderada), se $\mu_{1}<y^{*} \leq \mu_{2}$,

$y=2$ (diversificação moderada), se $\mu_{2}<y^{*} \leq \mu_{3}$,

$y=3$ (diversificação forte), se $\mu_{3} \leq y^{*}$

Por sua vez, o modelo de regressão latente é apresentado a seguir. Neste, são testadas relações entre diversas variáveis explicativas e o grau de diversificação agrícola na região estudada. Tais fatores explanatórios são relacionados principalmente com as discussões levantadas no referencial teórico, como tamanho da propriedade (porte do produtor), nível de instrução (educação formal, experiência, acesso à internet e assistência técnica), organização social (participação em associação) e tecnologia empregada (posse de algum tipo de certificado e adoção de cuidados pós-colheita). Contudo, adicionalmente, foram testadas as relações entre o grau de diversificação do produtor e variáveis como participação das vendas sob contratos, participação das vendas via atravessadores e a participação de determinadas atividades na propriedade (as principais frutas produzidas no polo: acerola, banana, coco, goiaba, manga e uva).

$$
\begin{aligned}
& y^{*}=\text { dcol } \cdot \beta_{1}+\text { escol } \cdot \beta_{2}+\text { exper } \cdot \beta_{3}+ \\
& + \text { exper } \cdot \beta_{4}+\operatorname{contratp} \cdot \beta_{5}+\operatorname{contratp}{ }^{2} \cdot \beta_{6}+ \\
& + \text { atravp } \cdot \beta_{7}+\text { atravp }{ }^{2} \beta_{8}+\text { acerolap } \cdot \beta_{9}+ \\
& + \text { bananap } \cdot \beta_{10}+\operatorname{cocop} \cdot \beta_{11}+ \\
& + \text { goiabap } \cdot \beta_{12}+\text { mangap } \cdot \beta_{13}+\text { uvap } \cdot \beta_{14}+ \\
& + \text { diertif } \cdot \beta_{15}+\text { dassoc } \cdot \beta_{16}+ \\
& + \text { dastec } \cdot \beta_{17}+\text { dposcolh } \cdot \beta_{18}+\text { dnet } \cdot \beta_{19}+\varepsilon
\end{aligned}
$$

Em que: $y^{*}$ é não observado; dcol é uma variável dummy para colonos, que assume valor 1 para produtores com área plantada abaixo de cinco hectares (ha) e zero no caso contrário; escol refere-se aos anos de estudo formal do entrevis-

8. Na amostra analisada, não foram encontrados quaisquer produtores com valor calculado para o Índice de Diversificação de Simpson maior do que 0,80. tado; exper são os anos de experiência do mesmo;; contratp é o percentual da receita total da propriedade obtida através de contratos formais ou informais; atravp é o percentual da receita total da propriedade obtida através de vendas para compradores dentro da porteira, ou seja, via atravessadores ${ }^{10}$; acerolap, bananap, cocop, goiabap, mangap e uvap referem-se à participação da área plantada com cada uma dessas culturas sobre a área total plantada na propriedade ${ }^{11}$; dcertif é uma variável dummy para certificação, que toma valor 1 para produtores que possuem algum tipo de certificação e zero no caso contrário; dassoc é uma variável dummy para associativismo, que assume valor 1 para participantes de alguma associação de produtores e zero no caso contrário; dastec é uma variável dummy para assistência técnica, que assume valor 1 se o entrevistado sente-se satisfeito com a assistência técnica recebida e zero no caso contrário; dposcolh é uma variável dummy de adoção de cuidados pós-colheita, que toma valor 1 para produtores que efetuam algum procedimento sobre a fruta colhida e zero no caso contrário; e dnet é uma variável dummy para utilização de internet, que assume o valor 1 quando o entrevistado tem acesso a este recurso e zero no caso contrário.

Para a estimação, foram utilizadas informações de levantamento primário aplicado aleatoriamente junto a 173 produtores localizados nos perímetros irrigados Bebedouro, Maria Tereza e Senador Nilo Coelho, no Polo Petrolina-Juazeiro, durante os meses de outubro e novembro de 2009. Da composição da amostra, 127 entrevistas foram realizadas junto a produtores do Perímetro Senador Nilo Coelho, 25 em Maria Tereza, 15 em Bebedouro e outros seis em áreas adjacentes. Do total de entrevistados, 149 possuíam área irri-

9. Neste caso (exper), assim como para o caso das variáveis contratp e atravp, foram incluídos termos quadráticos, tendo como objetivo a verificação de influências não lineares sobre o grau de diversificação.

10. Neste caso, consideraram-se apenas atravessadores individuais, sendo excluída a participação de empresas atravessadoras como traders e indústrias de processamento.

11. Variáveis importantes no intuito de captar quais dentre as principais frutas produzidas no polo tendem a dificultar ou propiciar a adoção de estratégias de diversificação. 
126 - Adoção de Estratégias para Redução de Riscos: identificação dos determinantes da diversificação produtiva no Polo PetrolinaJuazeiro

gada inferior a 10 ha, 15 produtores irrigavam entre 10 e 100 ha, e nove irrigavam acima de 100 ha. Dessas entrevistas, para efeito da estimação econométrica, foram aproveitadas 146 observações, das quais foi possível extrair informações relativas às receitas com cada cultura explorada, necessária à construção da variável dependente, bem como às variáveis explicativas relacionadas anteriormente.

Vale destacar que o Perímetro Senador Nilo Coelho é o maior perímetro de irrigação do Polo Petrolina-Juazeiro. Em 2005, segundo a Companhia de Desenvolvimento dos Vales do São Francisco e do Parnaíba (BRASIL, 2010b), este perímetro respondia por $38 \%$ do total de áreas irrigadas, $27 \%$ do total de empresas rurais e $52 \%$ dos colonos que atuam nos municípios de Petrolina e Juazeiro. Por sua vez, os Perímetros Bebedouro e Maria Tereza também somam importância para o polo: respectivamente, $6 \%$ e $12 \%$ das áreas irrigadas, $4 \%$ e 9\% do número de empresas rurais, e $8 \%$ e 16\% do número de colonos. Outros perímetros importantes podem ser destacados na região, como Tourão, Maniçoba, Curaçá e Mandacaru, mas todos apresentam características semelhantes aos perímetros visitados durante o levantamento amostral. Ademais, a concentração das entrevistas em agricultores de pequeno porte vale-se da forte participação destes quando se considera o número de produtores que atuam no polo. Nesse sentido, enfatiza-se que a amostra deve representar satisfatoriamente as características da região e pode sintetizar conclusões a respeito dos determinantes da diversificação agrícola entre produtores.

\section{Resultados}

A estimação do modelo logit ordenado é apresentado na Tabela 1 (estatísticas descritivas relacionadas às variáveis do modelo estão no Anexo). Observa-se que o teste qui-quadrado da razão de verossimilhança (teste $L R$ ) apresentou valor de 92,43, o que indica que o modelo como um todo é estatisticamente significante quando com- parado com modelos sem variáveis explicativas (significância de 0,00). Além disso, o teste LR de proporcionalidade das probabilidades (likelihood ratio test) apresentou valor de 23,29 , indicando que a hipótese de equivalência do modelo entre as categorias não pode ser rejeitada (significância de 0,96$)$. Com relação ao número de observações (146), demonstra-se que foram excluídas as informações não respondidas pelos produtores, que foram identificados como missing values. Destaca-se que a estimação apresentada coincide com o desvio padrão do modelo de regressão robusto à heteroscedasticidade, o que indica a não ocorrência deste problema. Contudo, duas variáveis consideradas no modelo não se mostraram estatisticamente significantes, não sendo, portanto, fatores importantes para explicar a adoção de estratégias de diversificação por parte dos produtores estudados: tratam-se das variáveis anos de escolaridade e participação do cultivo de acerola $^{12}$.

A primeira indicação a ser feita sobre os parâmetros é que coeficientes positivos aumentam as chances de que a variável $y^{*}$ seja observada nas categorias mais altas, ou seja, nos estratos referentes a maiores graus de diversificação. Por outro lado, coeficientes negativos estariam associados à elevação das chances de ocorrência em categorias mais baixas, ou seja, de menor diversificação. Com relação ao intercepto, ele pode ser representado pelo corte de categorias, estimados da seguinte forma:

$y=0$ (especialização forte), se $y^{*} \leq 1,37$

$y=1$ (especialização moderada), se $1,37<y^{*} \leq 2,13$,

$y=2$ (diversificação moderada), se 2,13< $y^{*} \leq 5,20$, $y=3$ (diversificação forte), se $5,20 \leq y^{*}$

Dessa maneira, um produtor "médio" cujas características poderiam ser tratadas pela média de cada variável explanatória, teria probabilidades de $46,29 \%$ de ser fortemente especializado,

12. Com relação à escolaridade, os dados coletados não mostram grande variabilidade (muitos produtores com Ensino Fundamental), assim como no caso do cultivo da acerola (na soma das áreas dos entrevistados, apenas 3,4\% correspondem a esta exploração). 
Tabela 1. Estimação do modelo logit ordenado e do modelo de razão de probabilidades (variável dependente: grau de diversificação agrícola)

\begin{tabular}{|c|c|c|c|c|}
\hline \multirow{2}{*}{ Discriminação } & \multicolumn{3}{|c|}{ Modelo logit ordenado } & \multirow{2}{*}{$\begin{array}{c}\text { Modelo de probabilidades proporcionais } \\
\text { Razão de Probabilidade }(\exp (\beta))\end{array}$} \\
\hline & Coeficiente & Desvio padrão & Significância & \\
\hline Dummy Colono & $-1,36$ & 0,52 & 0,009 & 0,255 \\
\hline Anos de estudo & $-0,04$ & 0,05 & 0,436 & 0,959 \\
\hline Experiência & 0,20 & 0,08 & 0,022 & 1,217 \\
\hline Experiência $^{2}$ & $-0,0031$ & 0,0016 & 0,048 & 0,996 \\
\hline Contrato & 8,45 & 3,03 & 0,005 & 4673,674 \\
\hline Contrato $^{2}$ & $-8,22$ & 3,04 & 0,007 & 0,0002681 \\
\hline Atravessador & 7,68 & 3,11 & 0,014 & 2168,535 \\
\hline Atravessador ${ }^{2}$ & $-5,66$ & 2,77 & 0,041 & 0,0034 \\
\hline Acerola & $-1,04$ & 1,53 & 0,495 & 0,3522 \\
\hline Banana & $-2,49$ & 1,38 & 0,070 & 0,0824 \\
\hline Coco & $-3,85$ & 1,78 & 0,030 & 0,0212 \\
\hline Goiaba & $-4,29$ & 1,33 & 0,001 & 0,0136 \\
\hline Manga & $-3,84$ & 1,31 & 0,003 & 0,0213 \\
\hline Uva & $-6,71$ & 1,68 & 0,000 & 0,0012 \\
\hline Dummy Certificado & 1,58 & 0,96 & 0,099 & 4,864 \\
\hline Dummy Associado & $-0,78$ & 0,40 & 0,053 & 0,457 \\
\hline Dummy Assistência & 0,84 & 0,44 & 0,058 & 2,321 \\
\hline Dummy Pós-produção & 1,58 & 0,46 & 0,001 & 4,870 \\
\hline Dummy Internet & 1,48 & 0,73 & 0,042 & 4,423 \\
\hline № de obs. & & & 146 & \\
\hline LR $\chi^{2}{ }_{19}($ teste LR $)$ & & & 92,43 & \\
\hline LR $\chi_{38}^{2}$ (proporcionalid.) & & & 23,39 & \\
\hline
\end{tabular}

Fonte: Elaboração própria.

$18,51 \%$ de ser especializado moderadamente, $32,74 \%$ de ser diversificado moderadamente e $2,46 \%$ de ser fortemente diversificado. Essas probabilidades, portanto, seriam alteradas de acordo com mudanças nas variáveis explicativas, o que pode ser constatado na Tabela 2, que apresenta os efeitos marginais estimados sobre cada categoria ou grau de diversificação (Classe). A análise acerca de cada variável explanatória, portanto, será feita a seguir.

Primeiro, sobre a variável dummy de porte do produtor (colono), verifica-se que o fato de o produtor ser colono eleva a probabilidade de o mesmo ser fortemente especializado (Classe 1) em 32,57 pontos percentuais. Assim, se a probabilidade de o produtor ser Classe 1 equivale a 37,89\% se o mesmo não for colono, o fato de o mesmo ser caracterizado como colono, tudo o mais constante, eleva essa probabilidade para $70,46 \%{ }^{13}$.

13. Destaca-se que tais probabilidades são tomadas para um "produtor médio" (média da amostra), alterando-se ape-
Nota-se que a característica de ser colono eleva a probabilidade de ser Classe $1 \mathrm{em}$ detrimento de todas as outras classes, sendo que a probabilidade de ser Classe 2 passa de 18,69\% para 13,14\%; Classe 3 passa de $39,97 \%$ para $15,50 \%$; e Classe 4 , de $3,44 \%$ para $0,90 \%{ }^{14}$. Verifica-se que, no caso do Polo Petrolina-Juazeiro, o tamanho da propriedade agrícola deve mesmo interferir sobre a opção do produtor em adotar estratégias de diversificação, visto que o fato de o mesmo ser caracterizado como colono deve elevar de forma significativa as chances de ser fortemente especializado.

Por sua vez, a variável referente aos anos de experiência deve ser interpretada com cuidado. Primeiramente, deve-se chamar atenção ao fato

nas a variável em análise (neste caso, ser ou não colono) para calcular seu efeito marginal.

14. Novamente, destaca-se que tais probabilidades referem-se a um produtor com todas as características na média, alterando-se apenas a variável em análise para calcular seu efeito marginal. 
128 - Adoção de Estratégias para Redução de Riscos: identificação dos determinantes da diversificação produtiva no Polo PetrolinaJuazeiro

Tabela 2. Estimação dos efeitos marginais (\%) sobre categorias de diversificação

\begin{tabular}{|c|c|c|c|c|}
\hline Discriminação & Classe $1(\%)$ & Classe $2(\%)$ & Classe $3(\%)$ & Classe $4(\%)$ \\
\hline Dummy Colono & $32,57^{*}$ & $-5,56$ & $-24,47^{*}$ & $-2,54^{* *}$ \\
\hline Anos de estudo & 1,04 & $-0,09$ & $-0,85$ & $-0,10$ \\
\hline Experiência & $-4,90^{* *}$ & 0,40 & $4,02^{* *}$ & $0,47^{* * *}$ \\
\hline Experiência $^{2}$ & $0,08^{* *}$ & $-0,01$ & $-0,06^{* *}$ & $-0,01^{* * *}$ \\
\hline Contrato & $-2,10^{*}$ & 0,17 & $1,72^{*}$ & $0,20^{* *}$ \\
\hline Contrato $^{2}$ & $2,04^{*}$ & $-0,17$ & $-1,68^{*}$ & $-0,20^{* *}$ \\
\hline Atravessador & $-1,91^{*}$ & 0,16 & $1,57^{* *}$ & $0,18^{* *}$ \\
\hline Atravessador ${ }^{2}$ & $1,41^{* *}$ & $-0,12$ & $-1,16^{* *}$ & $-0,14^{* * *}$ \\
\hline Acerola & 0,26 & $-0,02$ & $-0,21$ & $-0,03$ \\
\hline Banana & $0,62 * * *$ & $-0,05$ & $-0,51^{* * *}$ & $-0,06$ \\
\hline Coco & $0,96^{* *}$ & $-0,08$ & $-0,79 * *$ & $-0,09 * * *$ \\
\hline Goiaba & $1,07^{*}$ & $-0,09$ & $-0,88^{*}$ & $-0,10^{* *}$ \\
\hline Manga & $0,96^{*}$ & $-0,08$ & $-0,79^{*}$ & $-0,09^{* *}$ \\
\hline Uva & $1,67^{*}$ & $-0,14$ & $-1,37^{*}$ & $-0,16^{*}$ \\
\hline Dummy Certificado & $-33,10^{* *}$ & $-4,51$ & $30,26^{* *}$ & 7,35 \\
\hline Dummy Associado & $19,27^{* *}$ & $-1,77$ & $-15,64^{* *}$ & $-1,85$ \\
\hline Dummy Assistência & $-20,74^{* *}$ & 2,92 & $16,10^{* *}$ & $1,72^{* * *}$ \\
\hline Dummy Pós-produção & $-37,56^{*}$ & 3,30 & $30,32^{*}$ & $3,94^{*}$ \\
\hline Dummy Internet & $-32,09 *$ & $-3,41$ & $29,18^{*}$ & 6,32 \\
\hline
\end{tabular}

Observações: * significância de $1 \% ;{ }^{* *}$ significância de $5 \% ; * * *$ significância de $10 \%$.

Classe 1 refere-se ao produtor fortemente especializado; Classe 2, ao especializado moderadamente; Classe 3, ao diversificado moderadamente; e Classe 4, ao fortemente diversificado.

As estimativas referem-se ao efeito marginal na média da amostra, ou seja, indicam as mudanças de probabilidade com base em um "produtor médio".

Fonte: Elaboração própria.

de que a relação desta variável com a diversificação não se mostra linear, mas sim quadrática. Nesse sentido, o efeito marginal terá os componentes tanto da variável "experiência" quanto da "experiência2". Assim, esse efeito irá variar de acordo com o nível de experiência do produtor. Para produtores pouco experientes, a elevação dos anos tende a reduzir a especialização; enquanto que, para produtores mais experientes, a elevação dos anos tende a reduzir a diversificação. Por exemplo:

1. Se o produtor for pouco experiente, passando de três (mínimo observado na amostra) para quatro anos de experiência, verifica-se que a probabilidade de o mesmo ser Classe 1 passa de $84,52 \%$ para 82,09\%. As chances de ocorrência nas demais classes, por sua vez, elevam-se de 7,59\% para $8,64 \%$ na Classe 2 ; de $7,50 \%$ para $8,80 \%$ na Classe 3 e de $0,40 \%$ para $0,47 \%$ na Classe 4 .

2. Se o produtor for muito experiente, passando de 49 para 50 anos de experiência (máximo observado na amostra), verifica-se que a probabilidade de o mesmo ser Classe 1 passa de $55,68 \%$ para $58,55 \%$. As chances de ocorrência nas demais classes, por sua vez, são reduzidas de 17,18\% para $16,56 \%$ na Classe 2; de 25,45\% para $23,38 \%$ na Classe 3 ; e de $1,70 \%$ para $1,52 \%$ na Classe 4.

Como observado, há uma tendência de diversificação a cada ano de experiência adquirido. Porém, existe um nível de experiência tal que essa tendência se inverte, passando a ser de especialização. No caso em questão, esse nível de aproximadamente 31 anos, quando a distribuição de probabilidades de ocorrência nas categorias consideradas equivale a $31,08 \%$ na Classe $1,17,99 \%$ na Classe 2, 46,33\% na Classe 3 e 4,60\% na Classe 4. A partir desse nível, o incremento dos anos de experiência tende a elevar as chances de ocorrência na Classe 1 e reduzir as probabilidades nas demais categorias. Na Figura 1, é ilustrada a rela- 
Figura 1. Efeito dos anos de experiência sobre as chances de diversificação

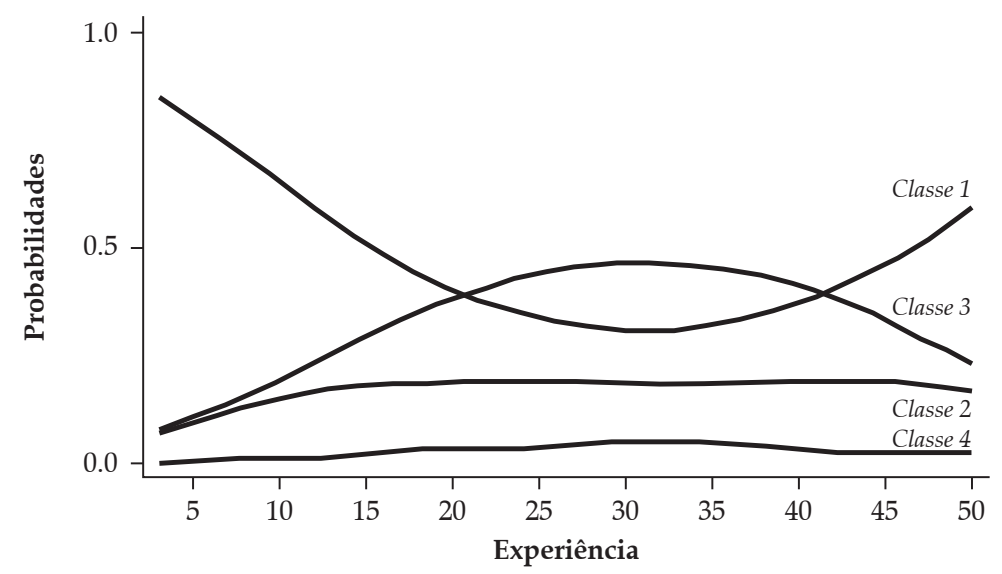

Fonte: Elaboração própria.

ção entre as probabilidades estimadas de diversificação e o nível de experiência dos produtores.

Com relação à variável de contrato, que diz respeito à participação da renda obtida de vendas através de contratos formais ou informais sobre a renda total do produtor, a interpretação é semelhante ao caso anterior, visto que os efeitos dessa variável têm tanto um componente linear quanto um quadrático. O efeito marginal disposto na tabela, tanto para "contrato" quanto para "contrato ${ }^{2 \prime}$, diz respeito aos efeitos trazidos por uma variação de uma unidade percentual na participação da renda obtida via contratos. Assim, esse efeito irá variar de acordo com o nível de participação dos contratos nas vendas do produtor. Para produtores que pouco vendem sob contrato, a elevação dessa participação tende a reduzir a especialização; enquanto que, para produtores que têm maior participação de contratos nas vendas, a elevação dessa participação tende a reduzir a diversificação. Por exemplo:

(i) Se o produtor se caracterizar por pouca participação por contratos nas vendas, passando de $0 \%$ para $1 \%$ de participação, verifica-se que a probabilidade de o mesmo ser Classe 1 passa de $55,38 \%$ para $53,30 \%$. As chances de ocorrência nas demais classes, por sua vez, elevam-se de 17,23\% para $17,61 \%$ na Classe 2; de $25,67 \%$ para $27,21 \%$ na Classe 3; e de 1,72\% para 1,87\% na Classe 4 .

(ii) Se o produtor se caracterizar por elevada participação de contratos nas vendas, passando de $99 \%$ para $100 \%$, verifica-se que a probabilidade de o mesmo ser Classe 1 passa de 47,78\% para $49,76 \%$. As chances de ocorrência nas demais classes, por sua vez, são reduzidas de $18,37 \%$ para $18,15 \%$ na Classe 2; de $31,52 \%$ para $29,94 \%$ na Classe 3; e de 2,32\% para 2,15\% na Classe 4.

Como observado, há uma tendência de diversificação a cada incremento das vendas sob contrato sobre o total de receitas do negócio. Contudo, existe um nível de participação tal que essa tendência se inverte, passando a ser de especialização. No caso em questão, esse nível é de $51,4 \%$, quando a distribuição de probabilidades de ocorrência nas categorias consideradas equivale a $12,41 \%$ na Classe $1,10,82 \%$ na Classe 2, 63,46\% na Classe 3 e 13,31\% na Classe 4. A partir desse nível, o incremento da participação tende a elevar as chances de ocorrência na Classe 1 e reduzir as probabilidades nas demais categorias. Na Figura 2, é ilustrada a relação entre as probabilidades estimadas de diversificação e a participação de contratos nas vendas dos produtores. 
130 - Adoção de Estratégias para Redução de Riscos: identificação dos determinantes da diversificação produtiva no Polo PetrolinaJuazeiro

Figura 2. Efeito dos contratos sobre as chances de diversificação

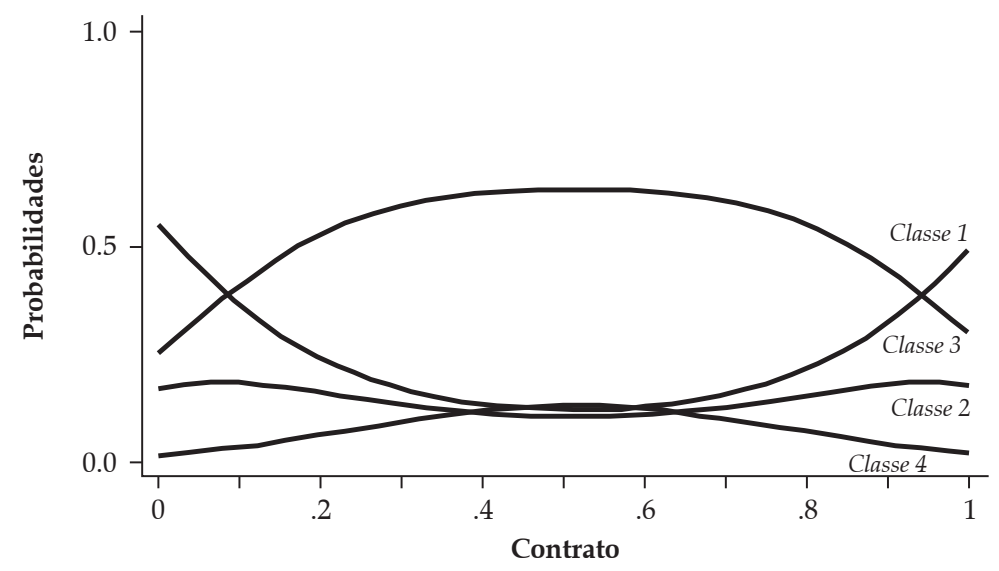

Fonte: Elaboração própria.

Quanto à variável atravessador, que diz respeito à participação da renda obtida de vendas via atravessadores (exceto traders ou indústrias de processamento), acontece algo semelhante ao ocorrido para contrato. Assim, o efeito marginal irá variar de acordo com o nível de participação das vendas via atravessadores no total de vendas do produtor. Para produtores que pouco vendem via atravessadores, a elevação dessa participação tende a reduzir a especialização; enquanto que, para produtores que têm maior participação de vendas via atravessadores, a elevação dessa participação tende a reduzir a diversificação. Por exemplo:

1. Se o produtor caracterizar-se por pouca participação de vendas via atravessadores, passando de $0 \%$ para $1 \%$ de participação, verifica-se que a probabilidade de o mesmo ser Classe 1 passa de 81,68\% para $80,51 \%$. As chances de ocorrência nas demais classes, por sua vez, elevam-se de $8,82 \%$ para 9,31\% na Classe 2; de 9,03\% para $9,65 \%$ na Classe 3; e de 0,49\% para $0,52 \%$ na Classe 4 .

2. Se o produtor caracterizar-se por elevada participação de vendas via atravessadores, passando de $99 \%$ para $100 \%$, verifica-se que a probabilidade de o mesmo ser Classe 1 passa de $36,41 \%$ para $37,25 \%$. As chances de ocorrência nas demais classes, por sua vez, são reduzidas de 18,61\% para $18,66 \%$ na Classe 2 ; de $41,32 \%$ para $40,56 \%$ na Classe 3 ; e de $3,66 \%$ para $3,53 \%$ na Classe 4.

Como observado, há uma tendência de diversificação a cada incremento das vendas via atravessadores. Contudo, existe um nível de participação tal que essa tendência se inverte, passando a ser de especialização. No caso em questão, esse nível é de $67,8 \%$, quando a distribuição de probabilidades de ocorrência nas categorias consideradas equivale a $24,80 \%$ na Classe $1,16,53 \%$ na Classe 2, 52,48\% na Classe 3 e 6,18\% na Classe 4. A partir desse nível, o incremento da participação tende a elevar as chances de ocorrência na Classe 1 e reduzir as probabilidades nas demais categorias. Na Figura 3, é ilustrada a relação entre as probabilidades estimadas de diversificação e a participação dos atravessadores nas vendas dos produtores.

Quanto às participações das culturas na área total plantada da propriedade, vale analisar os efeitos em grupo. A cultura que se mostra mais "concentradora" é uva, visto que a cada aumento de $1 \%$ na participação da cultura na área total plantada da propriedade, eleva-se a probabilidade de o produtor ser Classe 1 em 1,67\%. Em 
Figura 3. Efeito dos atravessadores sobre as chances de diversificação

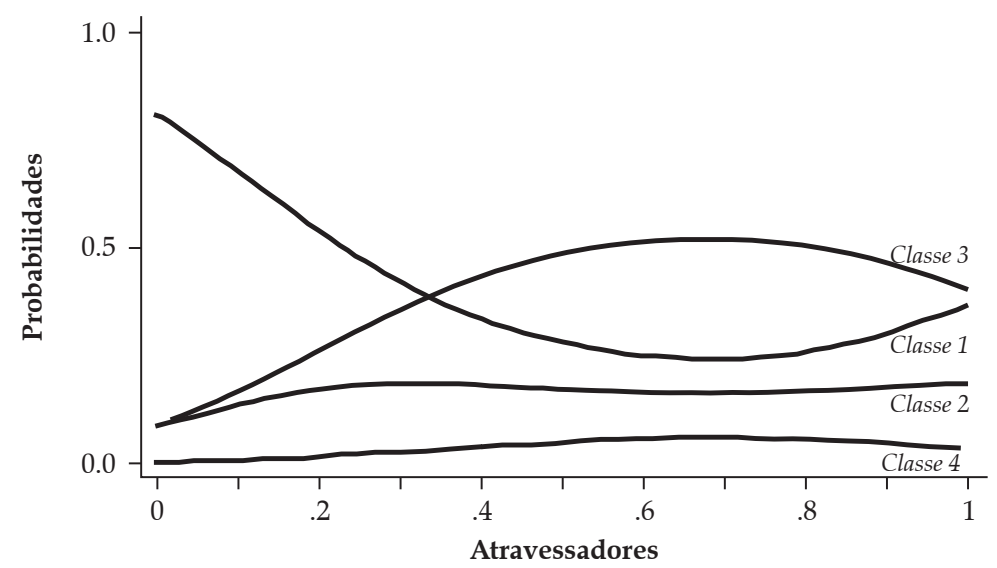

Fonte: Elaboração própria.

seguida, destacam-se goiaba, manga e coco, cujos aumentos de $1 \%$ na participação da área levam a crescimentos respectivos de $1,07,0,96$ e 0,96 ponto percentual sobre a probabilidade de o produtor se caracterizar por especialização forte. As demais culturas analisadas também são "concentradoras", ainda que em menor escala, caso da banana, com efeito marginal de $0,62 \%$, e acerola (insignificativo), com efeito de apenas $0,26 \%$.

Com respeito às variáveis dummy restantes, destaca-se que:

1. O fato de o produtor ser certificado eleva a probabilidade de o mesmo diversificar sua produção. Esse resultado está associado à incorporação tecnológica na unidade produtiva. Nesse sentido, se o produtor passar a ser certificado, tudo o mais constante, ele terá $17,25 \%$ de chances de ser caracterizado como Classe 1 (enquanto seria de $50,35 \%$ se o mesmo não fosse certificado); $13,56 \%$ de ser Classe 2 (18,07\% se não fosse certificado); $59,74 \%$ de ser Classe 3 (29,49\% para não certificados); e 9,45\% de ser Classe 4 (2,10\% se não fosse certificado).

2. Há tendência à concentração quando o produtor participa de algum tipo de associação de produtores. Isso se verifica no sentido de que, ao se associar, o produ- tor tem chances de 56,96\% de ser Classe 1 (37,69\% se não fosse associado); $16,91 \%$ de ser Classe 2 (18,68\% se não fosse associado); $24,51 \%$ de ser Classe 3 (40,15\% para não associados); e $1,62 \%$ de ser Classe 4 (3,47\% se não fosse associado).

3. Quanto à assistência técnica, produtores satisfeitos com este tipo de amparo têm chances de 40,77\% de ser Classe 1 (61,50\% se não tivessem esse tipo de assistência satisfatória); $18,75 \%$ de ser Classe 2 (15,84\% se não fossem assistidos); $37,42 \%$ de ser Classe 3 (21,32\% para os não assistidos); e 3,06\% de ser Classe 4 (1,34\% se não fossem assistidos satisfatoriamente). Assim, a obtenção de assistência técnica satisfatória para o produtor tende a elevar as chances de diversificação.

4. O fato de o produtor ter cuidados pós-colheita antes de realizar a venda da fruta eleva as chances de diversificação. Quando o produtor passa a efetuar esses procedimentos, a probabilidade de o mesmo ser Classe 1 cai para 29,20\% (seria de $66,75 \%$ se o produtor não adotasse esse cuidado); enquanto que tem chances de $17,64 \%$ de ser Classe $2(14,34 \%$ se não adotassem o cuidado); $48,16 \%$ de ser Classe $3(17,84 \%$ para os que não 
132 - Adoção de Estratégias para Redução de Riscos: identificação dos determinantes da diversificação produtiva no Polo PetrolinaJuazeiro

adotam); e 5,01\% de ser Classe 4 (1,07\% entre os que não adotam). Semelhante ao resultado da variável certificação, esse resultado está associado à incorporação tecnológica na unidade produtiva.

5. Por fim, quanto ao acesso à internet, produtores que usam este recurso tendem a reduzir a probabilidade de ser Classe 1 para $19,29 \%$ (seria de $51,37 \%$ caso o produtor não utilizasse); enquanto que tem chances de $14,51 \%$ de ser Classe $2(17,92 \%$ se não usasse o recurso); $57,87 \%$ de ser Classe 3 (28,69\% se não utilizasse); e $8,34 \%$ de ser Classe 4 (2,02\% entre os produtores que não utilizam). Novamente, associa-se esse resultado à incorporação tecnológica.

Vale salientar que os efeitos marginais referentes às Classes 2 e 4 mostraram-se, em sua maioria, insignificantes (no caso da Classe 4, ainda há certos efeitos significantes a 10\%). Esse resultado está associado às elevadas probabilidades de ocorrência nas Classes 1 e 3, ou seja, é mais provável que o produtor seja caracterizado por especialização forte e, em seguida, por diversificação moderada. Nesse sentido, se há alteração em certa característica do produtor e essa mudança reduz (ou eleva) a probabilidade de este ser Classe 1, isso ocorre principalmente em favor (ou em detrimento) das chances de ser Classe 3, e não das Classes 2 ou 4 . De fato, as probabilidades de o produtor ser Classe 2 ou Classe 4 são, por si, muito reduzidas e, assim, alterações nas características do produtor não devem levar a mudanças muito relevantes nas chances de ocorrência sobre estas categorias.

\section{Considerações finais}

Neste trabalho, procurou-se investigar o comportamento dos produtores agrícolas do Polo Petrolina-Juazeiro quanto ao gerenciamento de riscos em suas unidades produtivas, particularmente ao que diz respeito à adoção de estraté- gias de diversificação de culturas. Nesse aspecto, construiu-se um índice de diversificação que caracteriza o produtor segundo a diversidade de atividades que contribuem para a formação de renda do negócio. Além disso, foram relacionadas variáveis socioeconômicas e características da propriedade que poderiam determinar as razões de os produtores optarem pela diversificação produtiva.

Por meio da coleta de informações junto a 173 produtores da região, permitiu-se que a análise fosse realizada em nível microeconômico. Do total da amostra, 146 observações foram efetivamente utilizadas na estimação econométrica, com resultados que apontam para as seguintes variáveis que se relacionam de forma significativa com a diversificação de culturas: porte do produtor (colono), experiência, participação da receita advinda de contratos, participação da receita advinda de atravessadores, culturas específicas (banana, coco, goiaba, manga e uva), certificação, participação em associação, acesso à assistência técnica, adoção de procedimentos pós-colheita e acesso à internet. Vale salientar que a variável de escolaridade não se mostrou significativa, o que pode estar associado com a baixa variabilidade das observações e à grande concentração de produtores com nível de Ensino Fundamental.

Com relação ao tamanho da propriedade, foi possível verificar que os colonos do polo, aqueles que plantam menos de cinco hectares, tendem a especializar-se mais na exploração de poucas culturas relativamente a produtores de maior porte. Esse resultado mostrou-se coerente com a literatura internacional: a relação positiva entre tamanho da propriedade e diversificação é um sinal de que existem ganhos de escala no negócio.

A variável de anos de experiência mostrou que produtores do Polo que se caracterizam por maior tempo de vivência na agricultura tendem a adotar mais frequentemente estratégias de diversificação produtiva. Entretanto, quando o produtor possui mais de 31 anos de experiência, a probabilidade de este diversificar-se tende a diminuir com o tempo, em favor das chances de especialização. Esse resultado sugere que a relação entre experi- 
ência e adoção de estratégias de diversificação não é linear, ou seja, produtores menos experientes tendem a especializar-se em poucas atividades, $\mathrm{o}$ mesmo ocorrendo com aqueles que possuem muitos anos de experiência. Intuitivamente, até os 31 anos de experiência, produtores tendem a experimentar formas mais diversas de produção com o passar dos anos e, a partir de então, os mesmos se especializam naquelas culturas em que obtiveram maior adaptação.

Relações não lineares com a adoção de diversificação também foram encontradas com variáveis como vendas sob contrato e vendas via atravessadores. No primeiro caso, uma relação positiva com a diversificação é encontrada até um percentual de contratos em torno de $51,4 \%$ sobre o total de vendas realizadas e, a partir desse valor, as chances de especialização aumentam. Assim, produtores que vendem menos sob contrato tendem a especializar-se em poucas atividades, o mesmo ocorrendo com aqueles que possuem ampla participação de vendas sob contratos. Esse resultado mostra-se de acordo com o esperado, visto que produtores que utilizam contratos em suas negociações tendem a especializar-se nas atividades demandadas por seus clientes, esperando obter rendas seguras. Por outro lado, firmas que negociam apenas parte de suas vendas sob contrato são livres para experimentar outras atividades, adotando estratégias de diversificação. Contudo, se a maioria das negociações não é feita por meio de contrato, produtores tendem a elevar as chances de especialização.

Quanto à variável de percentual da receita do produtor atrelada à venda via atravessadores, contudo, pode-se afirmar que a prática de vender via atravessadores seja favorável às estratégias de diversificação, visto que as chances de adoção destas elevam-se até que o percentual de vendas via atravessadores chegue próximo a 67,8\% do total das receitas da firma. A partir desse percentual, apesar de as chances de diversificação se reduzirem, estas ainda são maiores que as chances de forte especialização.

Das variáveis associadas às principais culturas exploradas no polo, os resultados também se mostraram coerentes pois, com tudo mais constante, um aumento da área plantada com uma única cultura sempre deve elevar a probabilidade do produtor em se especializar. Porém, as magnitudes dos coeficientes mostraram que a atividade que mais intensifica o processo de especialização é a uva, seguida por goiaba, manga, coco e banana. Esse resultado pode estar associado ao fato de que o cultivo da uva é uma das principais atividades do polo voltadas para exportação, possuindo maior faturamento médio com relação às demais culturas.

Quanto a variáveis associadas à tecnologia empregada na propriedade, pode-se destacar que produtores certificados e, portanto, aqueles que possuem requisitos técnicos mais avançados, têm maior probabilidade de pertencerem ao grupo de mais diversificados. Da mesma forma, produtores que conduzem procedimentos pós-colheita tendem a experimentar mais a diversificação, $\mathrm{o}$ mesmo ocorrendo para aqueles que têm acesso à internet. De fato, produtores mais informados e melhor amparados tecnicamente têm maior propensão à redução de riscos.

Sobre a participação em organizações, verificou-se que produtores associados do polo tendem a diversificar menos suas atividades, resultado contrário à literatura pesquisada. Provavelmente, esse resultado está associado à própria concentração de prioridades e assuntos, no âmbito das associações atuantes no polo, amplamente voltadas a culturas já exploradas na região. Assim, leva-se a crer que as mesmas não estão direcionando o assunto da diversificação junto aos produtores associados. De maneira oposta, o acesso satisfatório à assistência técnica é positivamente relacionado com a adoção de estratégias de diversificação, o que pode indicar um direcionamento do conhecimento técnico ao processo de diversificação no polo.

Algumas variáveis como renda não agrícola e localização geográfica da propriedade seriam válidas a serem introduzidas no modelo. Entretanto, ao serem considerados tais fatores no processo de regressão, seus resultados não foram robustos e o modelo mostrou-se mal espe- 
134 - Adoção de Estratégias para Redução de Riscos: identificação dos determinantes da diversificação produtiva no Polo PetrolinaJuazeiro

cificado. Vale ainda salientar que os fatores que levam o produtor a diversificar suas atividades são acessados por poucos, como tecnologias e informação. Dessa forma, o que se conclui com o resultado do modelo é que a diversificação, como uma ferramenta para evitar riscos na agricultura é concentrada em produtores grandes e demais produtores com acesso a tecnologias.

Nesse contexto, caso seja desejado elevar o nível de diversificação produtiva local, é necessário, por um lado, que o produtor se conscientize de alguns dos aspectos supracitados referentes às suas próprias ações frente a seu empreendimento, tais como o de dar maior importância à exploração de culturas que viabilizem maior diversificação (tais como banana, coco e manga), bem como a aspectos referentes à adoção de boas práticas de manejo produtivo e de tecnologias avançadas (tais como aplicação de procedimentos de pós-colheita, uso de internet, certificação e assistência técnica).

Contudo, por outro lado, é também preciso se atentar a aspectos mais amplos, diretamente atrelados a políticas públicas, visando atender uma série de fatores aos quais o produtor local, sobretudo o pequeno, não apresenta condições de atender sozinho. Nesses termos, de acordo com os resultados obtidos, a disponibilização de linhas de crédito que viabilizem ao produtor atender alguns dos atributos colocados - como, por exemplo, investir em boas práticas de manejo produtivo e em culturas específicas, bem como aumentar o porte da propriedade e atender aos requisitos necessários à obtenção de certificados - aparece como um dos fatores primordiais para a diversificação produtiva local.

Ademais, cabe destacar que, segundo os resultados, políticas públicas de incentivos à atração de grandes firmas de processamento à localidade e de disseminação dos benefícios da organização de produtores em torno de associações/cooperativas - por meio de cursos, treinamentos, consultorias etc. - possibilitariam qualificar as relações contratuais observadas localmente. Porém, nesse caso específico, não necessariamente a especialização resultaria em perdas aos produtores, uma vez que viabilizaria, sobretudo aos colonos, se apoderarem de uma parcela maior dos excedentes de renda normalmente repassados na comercialização junto aos intermediários.

De modo geral, todas essas proposições procuram, no fundo, apontar para uma questão básica: se a intenção é melhorar as condições de vida dos produtores de fruta do Polo Petrolina Juazeiro, é necessário proporcionar condições favoráveis à produção no interior de suas propriedades, incorporando, no caso, fatores relacionados à redução dos seus riscos produtivos via diversificação. Nesses termos, seguindo tais proposições, espera-se que as lições gerais tiradas deste trabalho possam contribuir também em análises que busquem aperfeiçoar os mecanismos de diversificação produtiva para outras localidades, sinalizando possíveis meios para implantação de soluções nesse âmbito, devendo-se, contudo, considerar as especificidades locais em termos de cultivo, educação, tecnologia, dentre outros, como tratado neste trabalho.

\section{Referências bibliográficas}

BRASIL. Instituto Brasileiro de Geografia e Estatística IBGE. Pesquisa Agrícola Municipal - PAM, vários anos. In: Sistema IBGE de Recuperação Automática - SIDRA. Disponível em: <http://www.sidra.ibge.gov.br/>. Acesso em: 23 nov. 2010a.

BRASIL. Companhia de Desenvolvimento dos Vales do São Francisco e do Parnaíba - CODEVASF. Home page. Disponível em: <http://www.codevasf.gov.br/> . Acesso em: 23 nov. 2010b.

BRAVO-URETA, B. E., COCCHI, H. e SOLÍS, D. Output diversification among small-scale hillside farmers in El Salvador. OVE Working Papers, n.1706. Washington (USA): OVE/IADB, dez. 2006. 25p. Disponível em: <http://ideas.repec.org/p/ idb/ovewps/1706.html> . Acesso em: 23 nov. 2010.

CHAPLIN, H. Agricultural diversification: a review of methodological approaches and empirical evidence. Idara Working Paper, n. 2. London (UK): IDARA, Nov. 2000. 61p. Disponível em: <http://www.ilr1.uni-bonn. de/agpo/rsrch/idara/Farm/wyewp2.doc $>$. Acesso em: 23 nov. 2010. 
COELLI, T. e FLEMING, E. Diversification economies and specialization efficiencies in a mixed food and coffee smallholder farming system in Papua New Guinea. Agricultural Economics, v. 31, n. 2-3, p. 229-239. Milwaukee (USA): IAAE/Blackwell, Dec. 2004. Disponível em: <http://ideas.repec.org/a/eee/agecon/ v31y2004i2-3p229-239.html>. Acesso em: 23 nov. 2010.

CULAS, R. e MAHENDRARAJAH, M. Causes of diversification in agriculture over time: evidence from Norwegian farming sector. In: 11th International Congress of the European Association of Agricultural Economists, Annals... Copenhagen (Denmark): EAAE, Aug. 2005. 18p. Disponível em: <http://ideas.repec. org/p/ags/eaae05/24647.html>. Acesso em: 23 nov. 2010.

DELGADO, C. L. e SIAMWALLA, A. Rural economy and farm income diversification in developing countries. MSSD Discussion Paper, n. 20. Washington (USA): MSSD/IFPRI, out. 1997. 25p. Disponível em: <http://ideas.repec.org/p/fpr/mtiddp/20.html>. Acesso em: 23 nov. 2010.

FRASER, E. D. G. Crop diversification and trade liberalization: linking global trade and local management through a regional case study. Agriculture and Human Values, v. 23, n. 3, p. 271-281. Gainesville (USA): AFHV, 2006. Disponível em: <http://www. springerlink.com/content/25283w6698386v47/>. Acesso em: 23 nov. 2010.

GREENE, W. H. Econometric Analysis. 5. ed. New Jersey (USA): Prentice Hall, 2003.

GOULD, W., PITBLADO, J. e POI, B. Maximum likelihood estimation with Stata. 4. ed. College Station (USA): Stata Press, 2010.

HAJI, J. Production efficiency of smallholders' vegetable-dominated mixed farming system in Eastern Ethiopia: a non-parametric approach. Journal of African Economies, v. 16, n. 1, p. 1-27. Oxford (UK): CSAE, jan. 2007. Disponível em: <http://jae.oxfordjournals.org/ content/16/1/1.abstract >. Acesso em: 23 nov. 2010.

HEADY, E. O. Diversification in resource allocation and minimization of income variability. Journal of Farm Economics, v. 34, n. 4, p. 482-496. Milwaukee (USA): AAEA, nov. 1952. Disponível em: < http://www.jstor. org/pss/1233230> . Acesso em: 23 nov. 2010.

LIMA, J. P. R. e MIRANDA, E. A. A. Fruticultura irrigada no Vale do São Francisco: incorporação técnica, competitividade e sustentabilidade. Revista Econômica do Nordeste, v. 32, n. Especial, p. 611-632. Fortaleza-CE: ETENE/BNB, nov. 2001.
LLEWELYN, R. V. e WILLIAMS, J. R. Nonparametric analysis of technical, pure technical, and scale efficiencies for food crop production in East Java, Indonesia. Agricultural Economics, v. 15, n. 2, p. 113-126. Milwaukee (USA): IAAE/Blackwell, nov. 1996. Disponível em: <http://ideas.repec.org/a/eee/agecon/ v15y1996i2p113-126.html > . Acesso em: 23 nov. 2010.

MARKOWITZ, H. M. Portfolio selection: efficient diversification of investment. New York (USA) / London (UK): John Wiley \& Sons / Chapman \& Wall, 1959. 344p. Disponível em: <http://cowles.econ.yale. edu/P/cm/m16/m16-all.pdf > . Acesso em: 23 nov. 2010.

McKELVEY, R. D. e ZAVOINA, W. A statistical model for the analysis of ordinal level dependent variables. Journal of Mathematical Sociology, v. 4, n. 1, p. 103120. London (UK): Routledge, 1975. Disponível em: $<$ http://www.informaworld.com/smpp/content $\sim \mathrm{db}=$ all $\sim$ content $=$ a $926367164 \sim$ frm $=$ abslink $>$. Acesso em: 23 nov. 2010.

McNAMARA, K. T. e WEISS, C. Farm household income and on-and-off farm diversification. Journal of Agricultural and Applied Economics, v. 37, n. 1, p. 37-48. Athens (USA): SAEA, abr. 2005. Disponível em: <http://ideas.repec.org/a/ags/joaaed 43711.html>. Acesso em: 23 nov. 2010.

POPE, R. D. e PRESCOTT, R. Diversification in relation to farm size and other socio-economic characteristics. American Journal of Agricultural Economics, v. 62, n. 3, p. 554-559. Milwaukee (USA): AAEA, ago. 1980. Disponível em: <http://www.jstor.org/pss/1240214>. Acesso em: 23 nov. 2010.

RAHMAN, S. Whether crop diversification is a desired strategy for agricultural growth in Bangladesh. In: 82nd Annual Conference of the Royal Agricultural College, Analls... Cirencester (UK): AES, Mar.-Apr. 2008a. Disponível em: <http://ideas.repec.org/p/ags/ aes008/36867.html >. Acesso em: 23 nov. 2010.

RAHMAN, S. Determinants of crop choices by Bangladeshi farmers: a bivariate probit analysis. Asian Journal of Agriculture and Development, v. 5, n. 1, p. 29-42. Los Baños (Philippines): SEARCA, jun. 2008b. Disponível em: <http://ideas.repec.org/a/sag/ seajad/v5y2008i1p29-42.html > . Acesso em: 23 nov. 2010.

RAVISANKAR, T., SARADA, C. e KRISHNAN, M. Diversification of fish culture and exports among major shrimp-producing countries of Asia: a spatial and temporal analysis. Agricultural Economics Research Review (India), v. 18, n. 2, p. 187-195. Delhi (India): AERA, jul./dez. 2005. 
136 - Adoção de Estratégias para Redução de Riscos: identificação dos determinantes da diversificação produtiva no Polo PetrolinaJuazeiro

Disponível em: <http://ideas.repec.org/a/ags/aerrae/ 58470.html>. Acesso em: 23 nov. 2010.

SINGH, N. P., RANJIT, K. e SINGH, R.P. Diversification of Indian agriculture: composition, determinants, and trade implications. Agricultural Economics Research Review (India), v. 19, p. 23-36. Delhi (India): AERA, 2006. Disponível em: <http://ideas.repec.org/a/ags/ aerrae/57775.html>. Acesso em: 23 nov. 2010.

SMITH, E. G. e YOUNG, D. L. Cropping diversity along the U.S.-Canada border. Review of Agricultural Economics, v. 25, n. 1, p. 154-167. Milwaukee (USA): AAEA, 2003. Disponível em: <http://www.jstor.org/ pss/1349869>. Acesso em: 23 nov. 2010.

STATA, Data Analysis and Statistical Software. Home page. Disponível em: < http://www.stata.com/>. Acesso em: 23 nov. 2010.

WANG, X. e KOCKELMAN, K.M. Occupant injury severity using a heteroscedastic ordered logit model: distinguishing the effects of vehicle weight and type.
In: 84th Annual Meeting of the Transportation Research BoardForthcoming,Analls...Washington(USA):TRB,Jan. 2005. 21p. Disponível em: < http://citeseerx.ist.psu.edu/ viewdoc/download?doi=10.1.1.77.7939\&rep=rep1\&typ $\mathrm{e}=\mathrm{pdf}>$. Acesso em: 23 nov. 2010.

WHITE, T. e IRWIN, G. Farm size and specialization, p.23-32. In: BALL, G. e HEADY, E. (Eds.) Size, structure and future of farms. Ames (USA): ISUP, 1972. 404p.

WOLFE, F. e GOULD, W. An approximate likelihoodratio test for ordinal response models. Stata Technical Bulletin, v. 7, n. 42. College Station (USA): StataCorp LP, 1998. 52p. Disponível em: < http://ideas.repec.org/a/tsj/ stbull/y1998v7i42sg76.html>. Acesso em: 23 nov. 2010.

WU, S. e PRATO, T. Cost efficiency and scope economies of crop and livestock farms in Missouri. Journal of Agricultural and Applied Economics, v. 38, n. 3, p. 539-553. Athens (USA): SAEA, dez. 2006. Disponível em: <http://ideas.repec.org/a/ags/joaaed 43906.html>. Acesso em: 23 nov. 2010. 


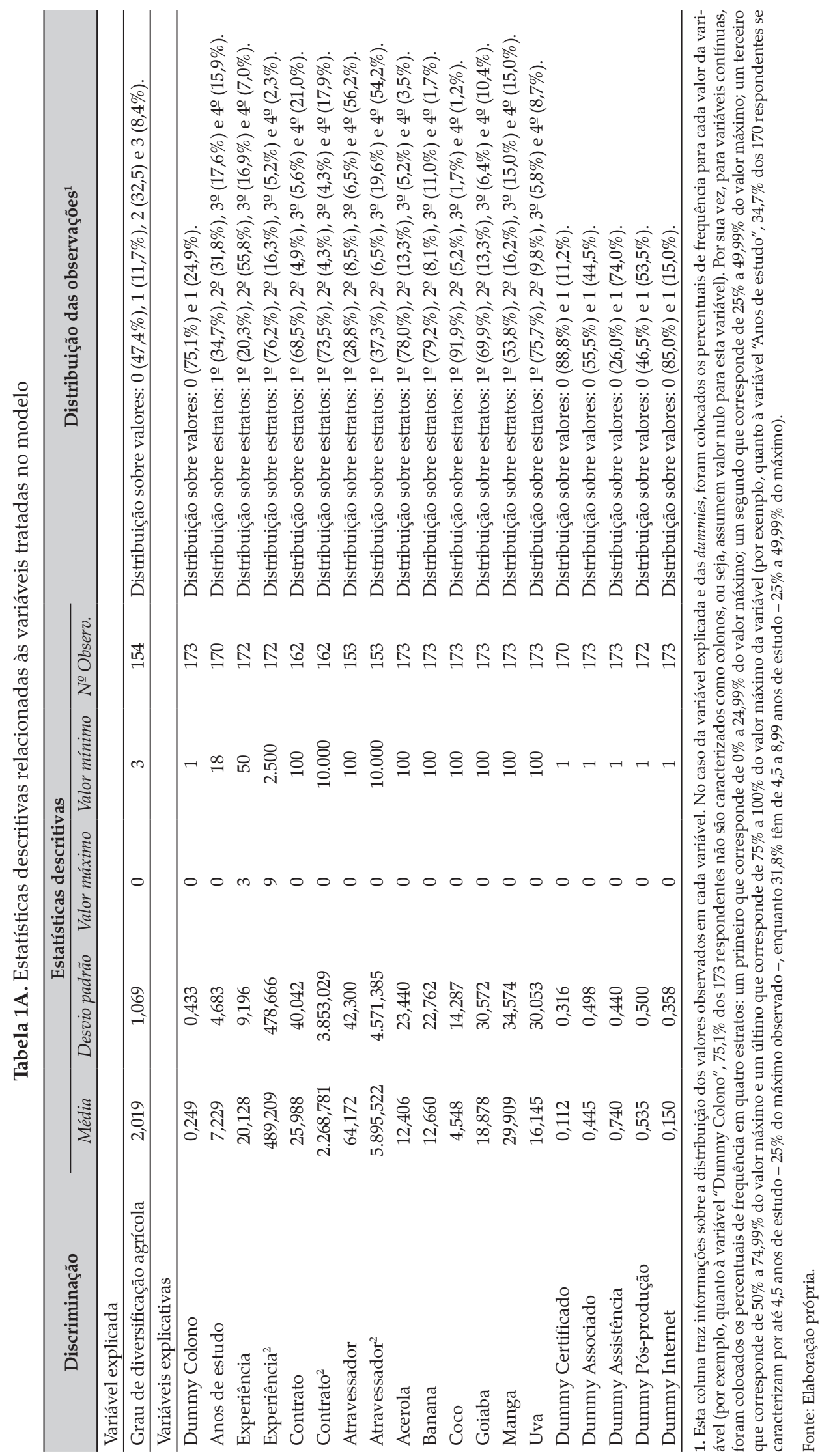

RESR, Piracicaba-SP, Vol. 52, № 01, p. 117-138, Jan/Mar 2014 - Impressa em Maio de 2014 